\title{
Chromosomal study of the lenoks, Brachymystax (Salmoniformes, Salmonidae) from the South of the Russian Far East
}

\author{
I.V. Kartavtseva*, L.K. Ginatulina, G.A. Nemkova and S.V. Shedko \\ Institute of Biology and Soil Science of the Far East Branch of the Russian Academy of Sciences, \\ Prospect 100 let Vladivostoku 159, Vladivostok 690022 \\ *Correspondent: irina-kar52@rambler.ru,shedko@ibss.dvo.ru
}

\begin{abstract}
An investigation of the karyotypes of two species of the genus Brachymystax (B. lenok and B. tumensis) has been done for the Russia Primorye rivers running to the East Sea basin, and others belonging to Amur basin. Based on the analysis of two species chromosome characteristics, combined with original and literary data, four cytotypes have been described. One of these cytotypes (Cytotype I: $2 n=90, N F=110-118$ ) was the most common. This common cytotype belongs to $B$. tumensis from the rivers of the East Sea basin and $B$. lenok from the rivers of the Amur basin, i.e. extends to the zones of allopatry. In the rivers of the Amur river basin, in the zone of the sympatric habitat of two species, each taxon has karyotypes with different chromosome numbers, $B$. tumensis $(2 n=92)$ and $B$. lenok $(2 n=90)$. Because of the ability to determine a number of the chromosome arms for these two species, additional cytotype have been identified for $B$. tumensis: Cytotype II with $2 \mathrm{n}=92, \mathrm{NF}=110-124$ in the rivers basins of the Yellow sea and Amur river and for B. lenok three cytotypes: Cytotype I: $2 \mathrm{n}=90, \mathrm{NF}=110$ in the Amur river basin; Cytotype III with $2 \mathrm{n}=90$, $\mathrm{NF}=106-126$ in the Amur river basin and Cytotypes IV with $2 \mathrm{n}=92, \mathrm{NF}=102$ in the Baikal lake.
\end{abstract}

Keywords: Brachymystax, chromosome, cytotype, karyotype, lenok, Salmonidae, variability

\section{INTRODUCTION}

Until recently the Brachymystax Gunther, 1866 genus has been considered to be monotypic with one species, B. lenok (Pallas, 1773), including two morphological forms as blunt- and sharp-snouted lenoks. Data about the chromosomal sets of lenoks $(2 n=90, N F=110-116)$ both for two forms have been reported without certain taxonomic conclusions (Frolov, 2000; Phillips and Ráb, 2001). Previously, information on the chromosomal set of sharpsnouted lenok, B. lenok for the area of the Amur River basin has been known from three sources: $2 \mathrm{n}=90, \mathrm{NF}=$ 106-136 (Makoedov, 1999), 2n=90, NF=108-126 (Chereshnev et al., 2002), 2n=90, $\mathrm{NF}=112$ (Ginatulina et al., 1998) and for another location, the Baikal Lake $2 n=92$, $\mathrm{NF}=102$ from one source (Dorofeeva, 1977). Information on the chromosomal set of blunt-snouted lenok, $B$. lenok has been presented for the area of the Yellow sea basin: $2 \mathrm{n}=90, \mathrm{NF}=110-118$ (Kang and Park, 1973; Xu et al., 2009); $2 \mathrm{n}=92, \mathrm{NF}=120$ (Wang and Wang, 1991) and for the Amur River basin: $2 \mathrm{n}=92, \mathrm{NF}=112$ (Viktorovsky et al., 1985). The number of chromosomes was stable for sharp-snouted lenok, $B$. lenok from two rivers of the Amur river basin $(2 n=90)$ and differs from the lenoks in the Baikal Lake $(2 n=92)$. As for blunt-snouted lenok, the number of chromosomes in one river of the Amur river basin and in a Korean river of the Yellow Sea basin was 92. However, in the river of China of the same basin the chromosome number was different, $2 n=90$.

The variation of the chromosome arm number in the published papers is presumably caused by the difficulty in determining biarmed, acro-, subtelo-, and submetacentric chromosomes even for one and the same fish. Each researcher may have his own opinion concerning number of the biarmed chromosomes which impacts arms number. The chromosome morphology could be different as well because of the variation in the degree of spiralization in chromosomes. In karyotype of B. lenok NF all investigators are shown different variability of the number of biarmed chromosomes.

In spite of the fact that Robertsonian's processes play an important role in the chromosome rearrangements of many fish species (Frolov, 2000; Phillips and Ráb, 2001), the differences in chromosome numbers as a result of the chromosome fusion/fission have not been discussed in 
the papers mentioned above. This is probably because numbers of the biarmed chromosomes in the two forms do not correlate with numbers of acrocentric chromosomes.

These forms have zones of allopatry and sympatry in the rivers of the East Asia and their taxonomic position is controversial (Chereshnev et al., 2002). Some authors have considered them to be intraspecific forms of B. lenok inhabiting in the rivers and lakes throughout eastern Siberia including portions of Kazakhstan, Mongolia, China and Korea (Alekseev, 1983; Mina, 1986; Osinov, 1990; Alekseev et al., 2003; Froufe et al., 2004; 2008; Alekseev and Osinov, 2006). Other authors have placed them in two independent different taxa of species rank (Kifa, 1976; Bogutskaya and Naseka, 2004). The investigation of the genetic characteristics in the places of their joint habitat, in sympatry, has revealed some differences of the two forms in the genome structure which suggested the existence of two species (Osinov et al., 1990; Osinov, 1991; 1993; Shedko et al., 1996; Oleinik and Skurikhina, 2006).

Recent revision of the morphological data and new diagnostic features of the skull (Shedko and Shedko, 2003) has distinctly revealed the presence of morphological differences between two nominal species: blunt-snouted lenok, B. tumensis Mori, 1930 from the Tumangan river with two synonyms (=B. lenok tsilingensis $\mathrm{Li}, 1996$ from the Yangtze, Yellow and Shensi rivers in China and $=B$. lenok czerskii Kirillov, 1979 from the Undyulyung river in Yakutia) and sharp-snouted lenok, B. lenok (Pallas, 1773) from Yenisei river in Siberia with three synonyms (=B. coregonoides Günther, 1866 from Ob, Irtysh, Yenisei, Hangar, Selenga, Lena, Vitim, Kolyma rivers and Baikal lake; =B. lenok savonovi, Mitrofanov, 1959, from Marka-kul lake in Altay; =B. swetowidowi Kirillov, 1962 from rivers of Siberia to east from $\mathrm{Ob}$ river basin).

The area where these two species occur covers the rivers of the Eastern Siberia and the rivers running into the Okhotsk Sea: such as Uda, Tugur, and Amur, including its tributaries. Blunt-snouted lenok, B. tumensis inhabits in the rivers flowing into the East Sea (Primorskii Krai in Russia, a northern part of the Korean Peninsula), Yellow Sea (China and Korea), Bolshoi Shantar Islands, northwest Sakhalin Island, North Korea and northeast China. A sharp-snouted lenok, B. lenok inhabits in the rivers of northeast Russia (Chereshnev et al., 2002).

In the papers, we cited above, the lenok karyotypes of two forms of sharp-snouted lenok, B. lenok have been described without indication their taxonomic rank. Until recently none of the papers had information on the karyotype of two forms from the same river. In connection with the appearance of morphological characteristics that prove the status of two nominal species, the question arises, what exact karyological peculiarities they have.
Thus, the first aim of this work is to study the karyotype of two lenok species from as allopatric, as sympatric habitats. The second aim is to investigate the karyotype of the blunt-snouted lenok, B. tumensis inhabiting rivers of the East Sea basin in first time. In addition, as a result of our data on the chromosome morphology, we are going to revise all information published on lenok's characteristics and give chromosome characterization for two species, B. tumensis and B. lenok.

\section{Materials ANd Methods}

The initial material (Fig. 1) to be studied includes bluntsnouted lenok, B. tumensis from Russia: Primorskii KraiNos 1-3 (our data) and Khabarovskii Krai - No 7 (Viktorovsky et al., 1985), from Korea No 5 (Kang and Park, 1973), from China No 6(Wang and Wang, 1991) and No 9 (Xu et al., 2009) and sharp-snouted lenok, B. lenok from Russia: Primorskii Krai-Nos 3-4 (our data), Khabarovskii Krai-Nos 7-8 (Makoedov, 1999; Chereshnev et al., 2002).

For karyological analysis the fishes were caught in the riverheads and transported in the alive types to the institute laboratory. The $B$. tumensis has been represented by two samples from two rivers of the East sea basin (allopatric area): the Vasilkovka river, No $1(n=6)$, and the Ananjevka river, No $2(n=3)$. Also one sample was taken from the Amur river basin (sympatric area), the Arsenjevka river, No $3(n=3)$. The collection of $B$. lenok has been represented by two samples from the Amur river basin, including the Arsenjevka river, No $3(n=1)$ and the Komissarovka river (sympatric area), No $4(n=1)$. No hybrids between $B$. tumensis and $B$. lenok in sampled specimens were found.

The chromosome preparations have been made from a kidney tissue by the direct method applied to mammals (Ford and Hamerton, 1956). In the laboratory, all fish were injected with colchicine $0.04 \%$ in abdominal space for 12-14 hours. The pronephros was crushed in hypotonic solution $(0.56 \% \mathrm{KCl})$ and was incubated for $20-25$ min at room temperature. After hypotonia, the cell pellet was fixed with a mixture of $96 \%$ ethanol and glacial acetic acid $(3: 1)$. The preparations were made by dropping the cell suspensions onto chilled, moist object glasses. The dried slides were stained with $2 \%$ acetoorcein or $2 \%$ azur-eosin (Giemsa dye, Merck, Germany). The stained chromosomal slides were analyzed under microscope Axioplan 2 imaging (Carl Zeizz, Germany) of Center of Collective Use of Microscopy Objects of the Institute of Biology and Soil Science, Russian Academy of Sciences, Far East Branch, Vladivostok. To study the chromosomal slides we used an AxioCam HR CCD-camera and AXIOVISION software (Carl Zeizz MicroImaging GmbH, Ger- 


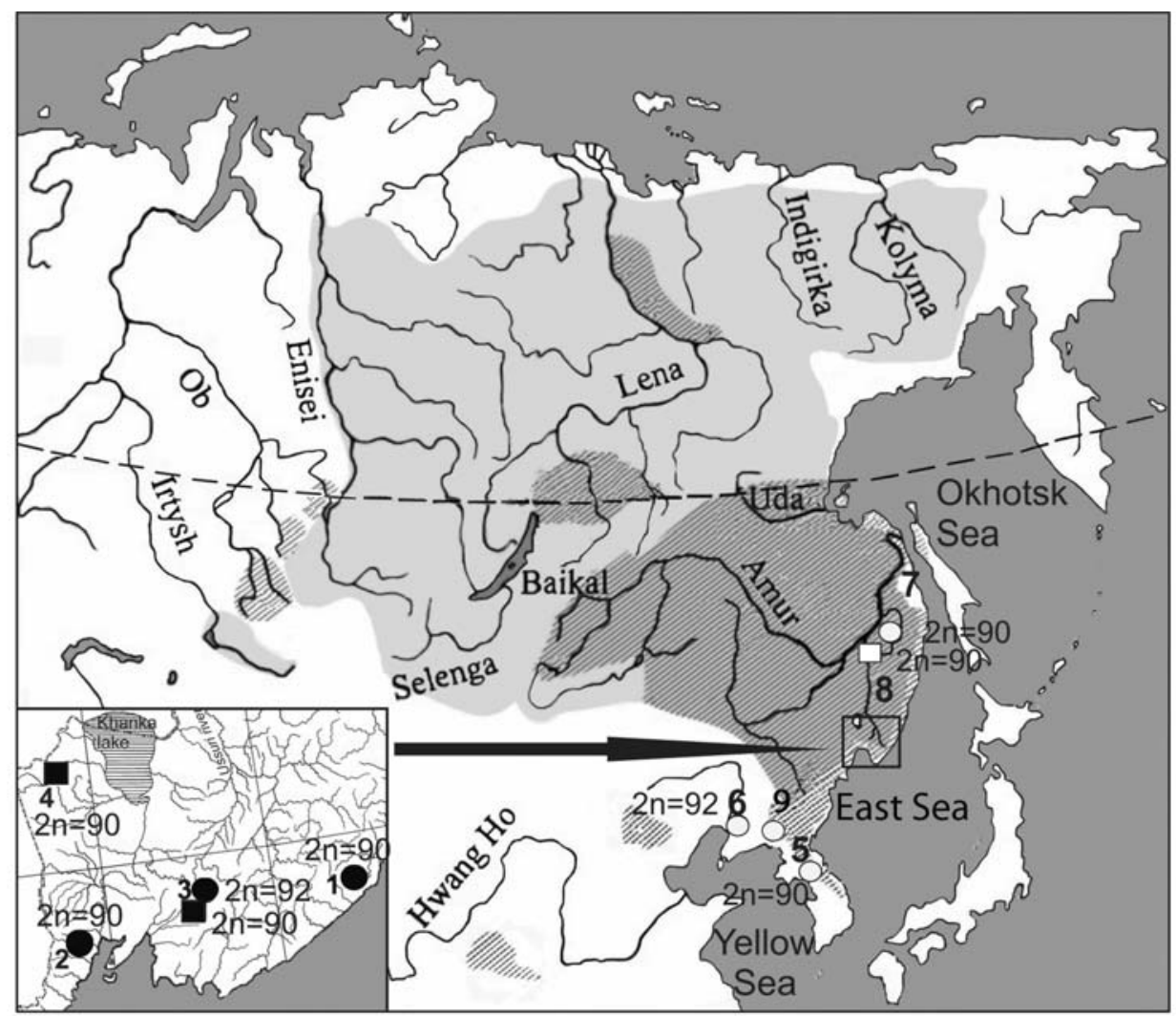

Fig. 1. The areals (by Froufe et al., 2008) and (localities of the karyotyped specimens) sampling locations of sharp-snouted, Brachymystax lenok and blunt-snouted, Brachymystax tumensis lenoks for karyotyping: 1-the Vasilkovka river(Russia); 2-the Ananjevka river (Russia); 3the Arsenjevka river (Russia); 4-the Komissarovka river(Russia); 5-the rivers from Korea; 6-the Luan He river (China); 7-the Amgun and Hor rivers (Russia); 8-the Anuj river (Russia); 9-the Yalu river(China). Grey shading and box-sharp-snouted lenok; left hatch and black circle - blunt-snouted lenok. Black box and circle-our data. White black box and circle-literary data.

Table 1. Distribution of chromosomal numbers in metaphase plates in Brachymystax tumensis and Brachymystax lenok.

\begin{tabular}{|c|c|c|c|c|c|c|c|c|c|}
\hline \multirow{2}{*}{ Species } & \multirow{2}{*}{ Locality } & \multirow{2}{*}{$\begin{array}{l}\text { Number of } \\
\text { individuals }\end{array}$} & \multicolumn{6}{|c|}{ Number of chromosomes } & \multirow{2}{*}{$\begin{array}{c}\text { Number of } \\
\text { metaphase plates }\end{array}$} \\
\hline & & & 88 & 89 & 90 & 91 & 92 & 93 & \\
\hline \multirow{3}{*}{ B. tumensis } & $1-2$ & 9 & 11 & 17 & 63 & 0 & 0 & 0 & 91 \\
\hline & 3 & 1 & 5 & 4 & 4 & 6 & 26 & 0 & 45 \\
\hline & 3 & 3 & 3 & 2 & 2 & 5 & 21 & 0 & 33 \\
\hline \multirow{2}{*}{ B. lenok } & 3 & 1 & 2 & 6 & 12 & 0 & 0 & 0 & 20 \\
\hline & 4 & 1 & 9 & 2 & 15 & 0 & 0 & 0 & 26 \\
\hline
\end{tabular}

many). In total 215 metaphase plates with clear morphology of chromosomes have been investigated (Table 1). Analyzing chromosome morphology we divided chromosomes into bi-armed chromosomes: metacentrics (M), submetacentrics (Sm), and mono-armed chromosomes: subtelocentrics and acrocentrics (St-A) according to the guidelines of known sources (Levan et al., 1964; Phillips and Ráb, 2001). Sometimes some authors scored subtelocentrics as bi-armed. To exclude polymorphism of chromosomes in the scoring of the subtelocentric chromosomes by di-erent authors we have analyzed ourselves a set of chromosomes from the published sources. The numbers of chromosomal arms from publications we have applied in two variants: original - NF and counted up by us - NF* (Table 2).

\section{Results AND Discussion}

On the basis of two variables, $2 \mathrm{n}$ and NF for the species of Brachymystax from the rivers of Primorye and published data, we found 4 cytotypes among collections: I- 
Table 2. Chromosomal characteristics of Brachymystax tumensis and Brachymystax lenok from the different parts of an areal.

\begin{tabular}{lclclccl}
\hline Species & Locality & Basin & Cytotype & $2 \mathrm{n}$ & NF & NF* & Source \\
\hline \multirow{6}{*}{ B. tumensis } & 1 & East Sea & I & 90 & 110 & - & Our data \\
& 2 & East Sea & I & 90 & 110 & - & Our data \\
& 5 & Yellow Sea & I & 90 & 116 & 110 & Kang and Park, 1973 \\
& 9 & Yellow Sea & I & 90 & 110 & 110 & Xu et al., 2009 \\
& 6 & Yellow Sea & II & 92 & 120 & 116 & Wang and Wang, 1991 \\
& 3 & Amur River & II & 92 & 116 & - & Our data \\
B. lenok & 7 & Amur River & II & 92 & $110-124$ & 116 & Viktorovsky et al., 1985 \\
& 3 & Amur River & I & 90 & 110 & 110 & Our data \\
& 4 & Amur River & III & 90 & 112 & 112 & Our data \\
& 7 & Amur River & III & 90 & $106-136$ & 112 & Makoedov, 1999 \\
& 8 & Amur River & III & 90 & $108-126$ & 116 & Chereshnev et al., 2002 \\
& $?$ & Baikal Lake & IV & 92 & 102 & no data & Dorofeeva, 1977 \\
\hline
\end{tabular}

1-the Vasilkovka river; 2-the Ananjevka river; 3-the Arsenjevka river; 4-the Komissarovka river; 5-the rivers from eastern Korea; 6-the Luan He river (China); 7-the Amgun and Hor Rivers (Khabarovskii Kray); 8-the Anuj river(Khabarovskii Kray); 9-the Yalu river(China).

$\mathrm{NF}^{*}$-our calculation from picture shown in article

- no data

(a)

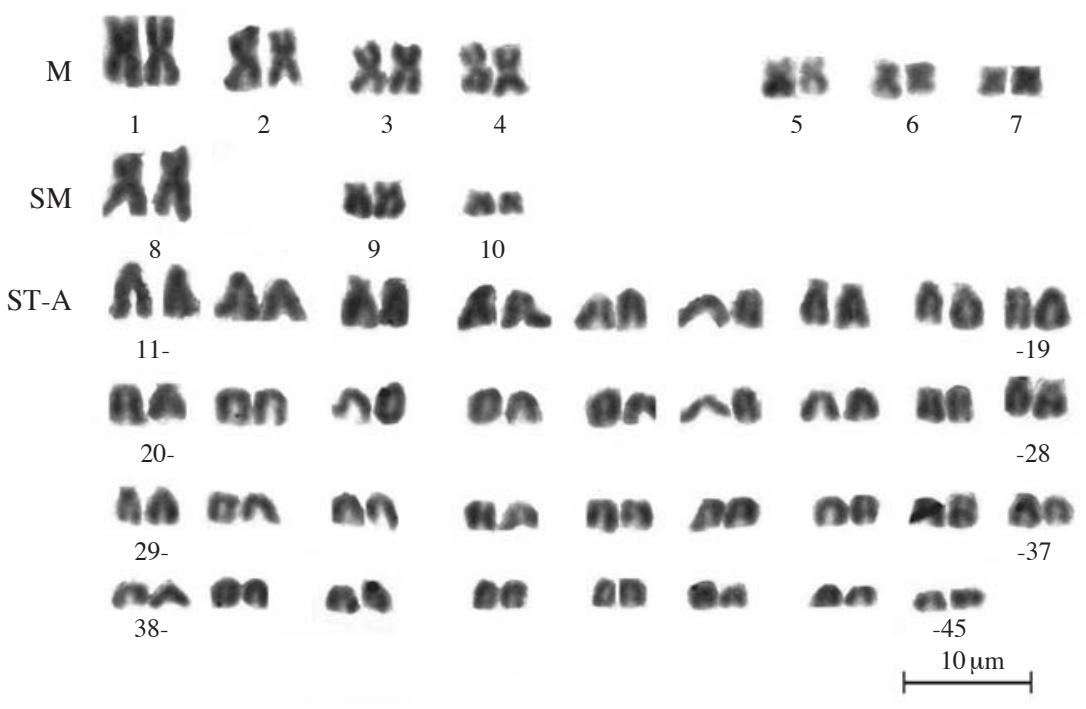

(b)
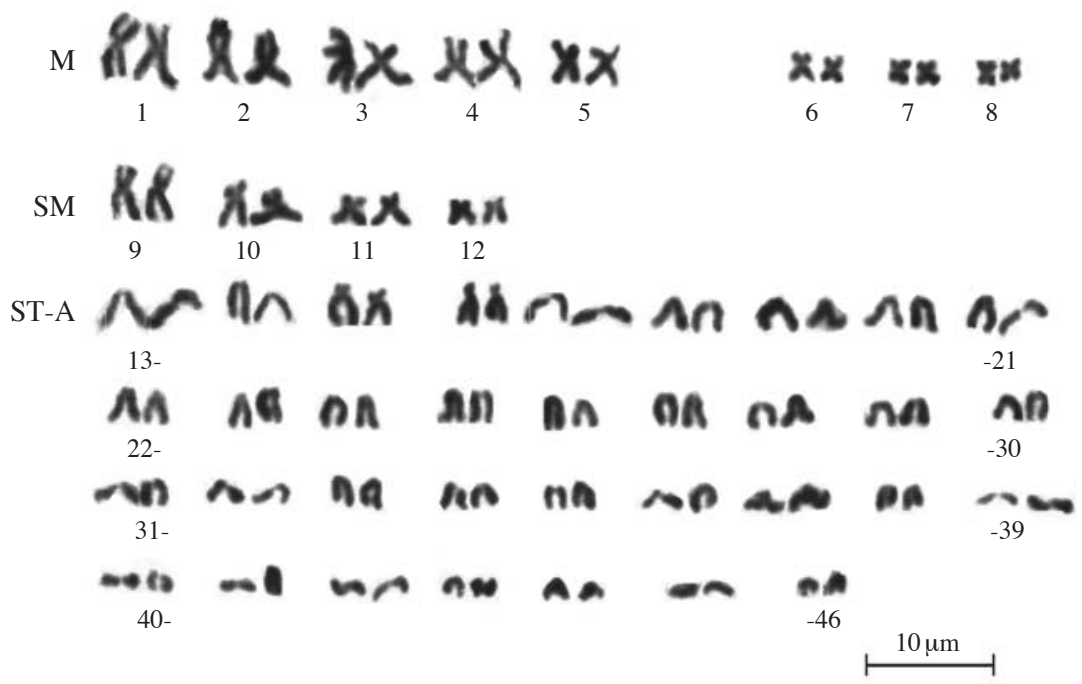

Fig. 2. Chromosomes of Brachymystax tumensis: a-chromosomal set of the lenok from the Ananjevka river, East sea basin $(2 \mathrm{n}=90$, $\mathrm{NF}=110$, cytotype I); b-chromosomal set of fish from the Arsenjevka river, Amur river basin $(2 \mathrm{n}=92, \mathrm{NF}=116$, cytotype II $)$. 


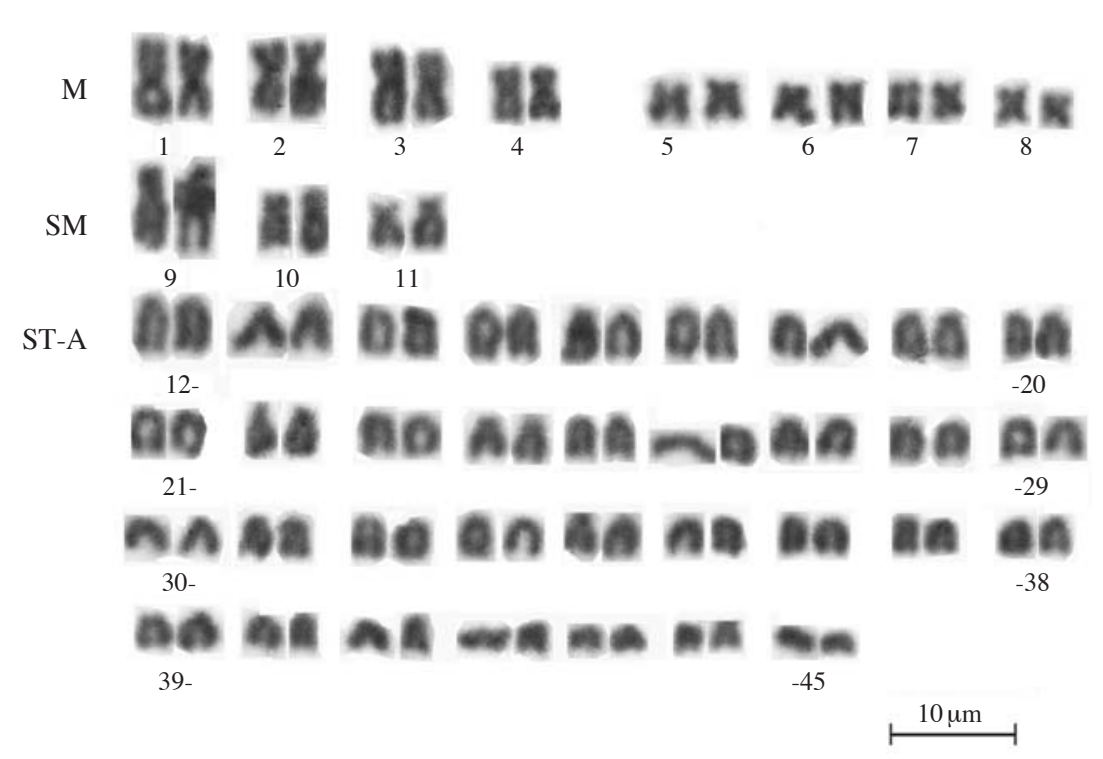

Fig. 3. Chromosomes of Brachymystax lenok $(2 \mathrm{n}=90, \mathrm{NF}=112$, cytotype III $)$ from - the Komissarovka river.

IV (Table 2).

B. tumensis. We have studied the karyotypes of this lenok species from the rivers of two basins, the Amur and in the East Sea. The modal number of chromosomes varies from 90 up to 92 (Table 1), NF from 110 to 116 . We have identified two cytotypes in this species (Fig. 2, Table 2). Both cytotypes had different number of the chromosome and number of chromosomal arms (NF).

$\mathbf{2 n}=\mathbf{9 0}, \mathbf{N F}=\mathbf{1 1 0}$. Cytotype I. Karyotype has $2 \mathrm{n}=90$, $\mathrm{NF}=110$ with 20 biarmed chromosomes, including 14 M: 8 large and 6 small and 6 SM. The 68 ST-A chromosomes smoothly decrease in size from large to small (Fig. 2a). All 9 individuals of B. tumensis from the rivers of the East Sea basin, the Vasilkovka River and the Ananjevka River had this karyotype. The same chromosomal characteristics were noted earlier for $B$. tumensis from Korea and China, the eastern area of the Yellow Sea basin, locality No 5 and No 9 (Fig. 1, Table 2).

$\mathbf{2 n}=92, \mathbf{N F}=116$. Cytotype II. Karyotype has $2 \mathrm{n}=92$ and $\mathrm{NF}=116$ with 24 biarmed chromosomes, including 16 M: 10 large and 6 small, 8 SM, 68 ST-A, smoothly decreasing in size from average down to small. This karyotype (Fig. 2b) was obtained for one individual of $B$. tumensis from the Amur River basin (the Arsenjevka river, locality 3), for western area of the Yellow Sea basin (the Luan He River in China, locality No 6), and for the Amur River basin (the Hor River, locality No 7).

Fish from the rivers of the East Sea basin have a stable karyotype with $2 \mathrm{n}=90$ (cytotype I). Fishes from the eastern area of the Yellow Sea basin have cytotypes with $2 \mathrm{n}=90$ (cytotype $I$ ) and fish from the western area of the Yellow Sea basin have karyotype with $2 \mathrm{n}=92$ (cytotype II). Fish from the Amur River basin have karyotype with
$2 \mathrm{n}=92$ (cytotype $I I$ ). As a whole, in chromosomal sets of B. tumensis we have found $2 \mathrm{n}=90$ and $2 \mathrm{n}=92$. In the cytotypes of $B$. tumensis we can see 4-5 pairs of large metacentrics and 3-4 pairs of small metacentrics. The differences between the cytotypes are caused by variability of A-ST and M-SM number of chromosomes.

Thus, for $B$. tumensis we have obtained variability for both variables, $2 \mathrm{n}$ and NF of M and SM chromosomes. B. tumensis from the rivers belonging to the East Sea and the Yellow Sea basins (cytotype I), differs from B. tumensis caught from the Amur river basin (cytotypes II) in the number of chromosomes ( $2 n=90$ against $2 n=92)$. Apparently, this distinction is caused by a different number of ST chromosomes. Proper determination of a number of ST chromosomes is very difficult and we admit the possibility to unite cytotype II.

B. lenok. Individuals of this fish have 90-92 chromosomes, NF varies from 110 up to 116 (Table 2, see NF* our calculation from picture shown in articles).

$\mathbf{2 n}=\mathbf{9 0}, \mathbf{N F}=110$. Cytotype $\mathbf{I}$. Karyotype has $2 \mathrm{n}=90$, $\mathrm{NF}=110$ with 20 biarmed chromosomes: $14 \mathrm{M}, 8$ large and 6 small, $6 \mathrm{SM}$ and 70 St-A. This karyotype characterized B. lenok individuals from the Amur River basin, the Arsenjevka river of locality No 3 and the Komissarovka river of locality No 4(Fig. 1). Note, that B. tumensis from the rivers of the East Sea basin has the same karyotype (cytotype I) (Fig. 2a).

$2 n=90, N F=106-136$. Cytotype III. One variant of this cytotype has $2 \mathrm{n}=90, \mathrm{NF}=112$ with 22 biarmed chromosomes: $18 \mathrm{M}, 8$ large and 8 small, $6 \mathrm{SM}$ and $68 \mathrm{St}-\mathrm{A}$ (Fig. 3). This karyotype is typical for $B$. lenok individuals from the Amur River basin, the Komissarovka River, locality No 4 . Another variants of this cytotype with NF 
vary from 108 up to 136 was detected on B. lenok from the Anuj river (Chereshnev et al., 2000), Amgun and Hor rivers (Makoedov, 1999) and Amgun river (our data) of the Amur River basin. If the calculation of short arms includes those accepted by us as ST chromosomes, then the NF of this cytotype was estimated as 118 .

2n=92, NF=102. Cytotype IY. The lenoks from the Baikal Lake basin have a karyotype of $2 n=92, N F=102$ (Dorofeeva, 1977; Dorofeeva, 1998; personal communication). The number of uni-armed and bi-armed chromosomes and a cytotype were not determined.

As a rule $B$. lenok karyotypes from the Amur River basin were 2 n $=90$ with two cytotypes (I and III). From the other basin, the Baikal Lake, B. lenok has a karyotype of $-2 n=92$. The $B$. lenok karyotype differs from the $B$. tumensis karyotype by four pairs of small metacentrics. The number of chromosomes as $2 n=92, N F=$ 102 was established for B. lenok from the Baikal Lake basin. Thus, based on our data and published data, it is possible to conclude that both, B. tumensis and B. lenok, can have two variants of chromosome number, $2 \mathrm{n}=90$ and $2 n=92$. However, in the Amur River basin, possibly because of sample size bias, the two lenok species had only one chromosome number: $B$. tumensis with $2 \mathrm{n}=92$, B. lenok with $2 \mathrm{n}=90$.

The variability of number and morphology of chromosomes in the cytotypes, found in fish from the various rivers, may be caused by pericentric inversions, while variability in $2 \mathrm{n}$ may be caused by aneuploidy, or by appearance of the additional or B chromosomes, that we could not exclude. For fish the polyploidy is also a possible factor in karyotype evolution (Phillips and Ráb, 2001). However, cases of intrapopulation polymorphism caused by the appearance of superfluous chromosomes are known for many species of plants and animals, including fish (Vasil'ev, 1985; King, 1993; Camacho et al., 2000; Frolov, 2000; Kartavtseva, 2002; Feldberg et al., 2004). Sometimes B chromosomes are revealed in the zones of species hybridization (Camacho, 2005) or in the animals with the different cytotypes in a hybrid zone (Ivanitskaya et al., 2008). The B chromosomes are known in many freshwater fish species. The origin of B chromosomes in the fish, as well as in other animals, would be caused by either chromosomal breakdowns in fish due to mutagenetic action in aquatic environment or due to hybridization events (Feldberg et al., 2004). However, we consider aneuploidy to be more probable than other types of chromosome number variability. The reproductive isolation between $B$. tumensis and B. lenok from the Amur river basin may not be absolute and in some cases their hybridization possible (Alekseev, 1983; Osinov et al., 1990; Osinov, 1993) now or in the past (Shedko et al., 1996, and other our not published data). Therefore, in our opinion, the observed chromosomal polymorphism at B. tum- ensis from the different basins could be explained by interspecific hybridization in rivers of the Amur basin where two species inhabit in sympatry. Hopefully, further investigation of the karyotypes of two species (B. lenok and $B$. tumensis) from the rivers of the various basins jointly with the molecular genetic methods would better explain both intra- and interspecific chromosome variability in Brachymystax genus.

\section{Conclusion}

Overall, based on our data and published data on $B$. tumensis and $B$. lenok chromosome characteristics, the similarity and distinction of their karyotypes have been shown. In total four cytotypes have been described for the species, one of which (Cytotype I: $2 \mathrm{n}=90, \mathrm{NF}=110$ ) turned out to be common for both species form different basins. The Cytotype I has been found in B. tumensis from the rivers of the East Sea basin and B. lenok from the Amur river basin, i.e. in the zone of allopatry. In the rivers of the Amur basin (zone of sympatry) two species have karyotypes with a different chromosome number. However, it was difficult to calculate a number of the chromosome arms of these species in the rivers of the Amur basin, for B. tumensis $-2 \mathrm{n}=92, \mathrm{NF}=110-124$, whereas for $B$. lenok $-2 \mathrm{n}=90, \mathrm{NF}=110-136$. In addition, a number of chromosomes equal to 92 are known for $B$. lenok from the Baikal Lake and for B. tumensis from the Luan He river(China). Perhaps, the further investigation of the karyotypes of two lenok species caught from the rivers of the different basins with using molecular genetic methods in the research would allow us to explain intraand interspecific variability of the chromosomes in the Brachymystax genus.

\section{ACKNOWLEDGEMENTS}

The authors thanks for English corrections R. Phillips, Department of Biological Sciences, University of Wisconsin-Milwaukee and the Russian Foundation of Fundamental Research for support under grants no 09-04-01390a, 09-04-00370a, and Far Eastern Branch of Russian Academy of Science grant no 09-II-CO-06-007, 12-II-CO06-018, as well as by technical support from the Center of Collective Use of Microscopy Objects of the Institute of Biology and Soil Science, Russian Academy of Sciences, Far East Branch, Vladivostok.

\section{REFERENCES}

Alekseev, S.S. 1983. Morpho-ecological characteristics of 
lenoks (Brachymystax, Salmonidae, Salmoniformes) from the Amur River basin and from the Uda River. Zoologicheskii Zhurnal 62:1057-1068 (in Russian).

Alekseev, S.S., A.F. Kirillov and V.P. Samusenok. 2003. Distribution and morphology of the sharp-snouted and the blunt-snouted lenoks of the genus Brachymystax (Salmonidae) of East Siberia. Journal of Ichthyology 43:311-333.

Alekseev, S.S. and A.G. Osinov. 2006. Blunt-snouted lenoks (Genus Brachymystax: Salmoniformes, Salmonidae) from the Ob' Basin: New data on morphology and allozyme variation. Journal of Ichthyology 46:500-516.

Bogutskaya, N.G. and A.M. Naseka. 2004. Catalogue of agnathans and fishes of fresh and brackish waters of Russia with comments on nomenclature and taxonomy. Moscow: KMK Scientific Press Ltd. 389 pp.

Camacho, J.P.M., T.F. Sharbel and L.W. Beukeboom. 2000. B chromosome evolution. Philosophical Transactions. B 355:163-178.

Camacho, J.P.M. 2005. B chromosomes. The evolution of the genome (pp. 223-286). In: T. Ryan Gregory (ed.), Burlington, San-Diego, London. 740 pp.

Chereshnev, I.A., V.V. Volobuev, A.V. Shestakov and S.V. Frolov. 2002. Salmonidae fishes in Russian North-East. Vladivostok, Dalnauka. 496 pp (in Russian).

Dorofeeva, E.A. 1977. Utilization of karyological data for solving problems of systematics and phylogeny of salmonids. The principles of the classification and phylogeny of the salmonoid fishes. Leningrad. Zoological Institute Russian Academy of Sciences 86-95 (in Russian).

Feldberg, J.I.R. Porto, M.N. Alves-Brinn, M.N.C. Mendonca and D.C. Benzaquem. 2004. B chromosomes in Amazonian cichlid species. Cytogenetic and Genome Research 106:195-198.

Ford, C.E. and J.L. Hamerton. 1956. A colchicine, hypotonic citrate, squash sequence for mammalian chromosomes. Stain Technology 31:247-251.

Frolov, S.V. 2000. Karyotype variability and evolution in Salmonidae. Vladivostok, Dalnauka. 229 pp(in Russian).

Froufe, E., K.M. Sefc, P. Alexandrino and S. Weiss. 2004. Isolation and characterization of Brachymystax lenok Microsatellite loci and cross-species amplification in hucho spp. and Parahucho perryi. Molecular Ecology Notes 4: 150-152.

Froufe, E., S. Alekseyev, P. Alexandrino and S. Weiss. 2008. The evolutionary history of sharp- and blunt-snouted lenok (Brachymystax lenok (Pallas, 1773) and its implications for the paleo-hydrological history of Siberia. BMC Evolutionary Biology 8:40.

Ginatulina, L.K., I.V. Kartavtseva, S.V. Shedko and G.A. Nemkova. 1998. Karyological analysis of two forms of Brachyomystax lenok (Pall.) from sympatric and allopatric populations of Primorye. Modern achievements in population, evolutionary and ecological genetics (MAPEEG - 1998): International Symposium Vladivostok-Vos- tok Marine Biological station, Vladivostok, September 3-8, 1998:6-7.

Ivanitskaya, E., M. Sözen, L. Rashkovetsky, F. Matur and E. Nevo. 2008. Discrimination of $2 \mathrm{n}=60$ Spalax leucodon cytotypes (Spalacidae, Rodentia) in Turkey by means of classical and molecular cytogenetic techniques. Cytogenetic and Genome Research 122:139-149.

Kang, Y.S. and E.H. Park. 1973. Somatic chromosomes of the Manchurian trout, Brachimystax lenok (Salmonidae). Chromosome Information Service 15:10-11.

Kartavtseva, I.V. 2002. Karyosystematics of wood and field mice (Rodentia, Muridae).

Kifa, M.I. 1976. Morphology of two forms of lenok (genus Brachymystax, fam. Salmonidae) from the Amur basin and their systematic position. In Zoogeografiya i sistematika ryb (Zoogeography and systematics of fishes) Edited by: Skarlato. Zoological Institute of the Academy of Sciences of the USSR Publishing House, Leningrad. 142-156 (in Russian).

King, M.A. 1993. Species Evolution: The role of chromosome change. Cambrige University Press. 336 pp.

Levan, A., K. Fredga and A.A. Sandberg. 1964. Nomenclature for centromeric position on chromosomes. Hereditas 52:201-220.

Makoedov, A.N. 1999. Karyology, biocamical genetics and population phenetics salmon fish from Siberia and the Far East: comparative aspects. Moscow, UMK, Psikhologiya. 291 pp (in Russian).

MA Bo, J IAN G and Zuo Fa. 2007. Genetic diversity and relationship between two species of Brachymystax in Wusuli River revealed by microsatellites. Journal of Fishery Sciences of China 14:39-45 (in Chinese).

Oleinik, A.G. and L.A. Skurikhina. 2008. Phylogenetic relationships of Sakhalin Taimen Parahucho perryi inferred from PCR-RFLP analysis of mitochondrial DNA. Russian Journal of Genetics 44:767-776.

Osinov, A.G. 1991. Genetic divergence and phylogenetic relationships between lenoks of genus Brachymystax and huchens of genera Hucho and Parahucho. Genetika (Moscow) 27:2127-2135 (in Russian).

Osinov, A.G. 1993. Counter current dispersal, secondary contacts, and speciation in lenoks of the genus Brachymystax (Salmonidae, Salmoniformes). Genetika (Moscow) 29: 654-669.

Osinov, A.G., I.I. Il'in and S.S. Alekseyev. 1990. Forms of lenok, Brachymystax (Salmoniformes, Salmonidae) delineated by genetic analysis. Journal of Ichthyology 30:138153 (in Russian).

Phillips, R. and P. Réb. 2001. Chromosome evolution in the Salmonidae (Pisces): an update. Biological Reviews 76: $1-25$.

Shedko, S.V., L.K. Ginatulina, I.Z. Parpura and A.V. Ermolenko. 1996. Evolutionary and taxonomic relationships among Far-Eastern salmonid fishes inferred from mito- 
chondrial DNA divergence. Journal of Fish Biology 49: 815-829.

Shedko, S.V. and M.B. Shedko. 2003. New data on freshwater ichthyofauna of the south of the Russian Far East. Vladimir Ya. Levanidov's biennial memorial meetings. Issue 2. Dal'nauka, Vladivostok: 319-336 (in Russian).

Vasil'ev, V.P. 1985. Evolutionary karyology of fish. Moskow, Nauka. 300 pp (Monograph in Russian).

Viktorovsky, R.M., A.N. Makoedov and A.A. Shevchishin. 1985. The chromosomal sets of Brachymystax lenok and Hucho taimen and the divergency of the salmonid genera. Tstiologiya 27:703-709 (in Russian).
Vladivostok, Dal'nauka. 142 pp. (Monograph in Russian, summary, tables and figures in English).

Wang, J. and S. Wang. 1991. The preliminary study of the karyotype of Brachymystax lenok. Salmon fishery 4:2427 (in Chinese).

Xu, G.-F., Zh.-bo. Mu, Sh.-Q. Xue, Y.-Y. Zhang, Y.-F. Li, J. Du and Y.-Ch. Chen (2009) Analysis on genetic polymorphism of chromosome of Brachymystax lenok in different valleys Acta hydrobiologica Sinica 33:975-979 (in Chinese).

Submitted: November 23, 2012, Accepted: February 6, 2013 